\title{
REPRESENTAÇÕES SOCIAIS DE ALUNAS DO CURSO DE PEDAGOGIA: EXPECTATIVAS EM RELAÇÃO A FORMAÇÃO DOCENTE
}

\author{
Rita de Cássia PETRENAS ${ }^{1}$ \\ Valéria Marta N. MOKWA ${ }^{2}$ \\ Fátima Coelho GONINI ${ }^{3}$
}

\begin{abstract}
RESUMO: O presente estudo analisou as representações de alunas do curso de Pedagogia em relação aos processos de escolarização e a formação docente. A pesquisa fundamenta-se na teoria moscoviciana das representações sociais, em estudos sobre a formação docente e a trajetória de escolarização. O trabalho apresentou quatro etapas que se sucederam durante o período de formação no curso de Pedagogia, sendo que três das mesmas consistiu na elaboração de redações pelas estudantes em três momentos no decorrer do curso, para finalizar foram realizadas a gravação de entrevistas com as discentes. Os dados foram analisados através da análise de conteúdo, modalidade temática, depreendendo-se núcleos de significação. As representações construídas pelas participantes tem como elemento marcante, a deficiência do ensino básico público, dificultando o acesso a universidade pública e boa formação profissional, constituindo o núcleo figurativo da representação social. As futuras pedagogas revelaram também insegurança e medo em relação ao exercício da profissão docente, mas também indicaram pontos positivos do curso marcados pela criticidade, reflexão e uma inserção melhor no mercado de trabalho. Foi possível constatar a importância da formação docente para a melhoria do ensino, principalmente dos educadores que atuarão nos primeiros anos processo de escolarização, formação essa que deve ser pautada na relação entre teoria e prática e também no resgate do papel do educador na sociedade atual.
\end{abstract}

PALAVRAS-CHAVE: Representações sociais. Formação docente. Curso de pedagogia.

Nos últimos anos estudos sobre a docência, principalmente em relação à formação de profissionais que atuam na educação básica, vêm instigando pesquisas na busca da apreensão de como o docente interage com seu próprio cotidiano escolar, bem como, com sua formação antes e/ou durante o ingresso na profissão escolhida. (TARDIF; LESSARD, 2007; PIMENTA; LIMA, 2004; TURA, 2005; MIZUKAMI, 1996).

Esses estudos advertem sobre a necessidade de compreender a trajetória e as concepções dos educandos dos cursos de formação de professores, conhecido na atualidade como Curso de Pedagogia, pois, o pedagogo é um dos responsáveis pelo desenvolvimento do educando, visto que, a formação de um ser crítico, reflexivo, bem como, a formação do

\footnotetext{
1 UNICEP - Centro Universitário Paulista. Curso de Pedagogia. Porto Ferreira - SP - Brasil. petrenas@bol.com.br

${ }^{2}$ Faculdade de Ituverava. Curso de Pedagogia. Integrante do NUSEX Núcleo de Estudos da Sexualidade (UNESP). Ituverava - SP - Brasil. valeriamokwa@gmail.com

${ }^{3}$ Faculdade de Ituverava. Professora no Curso de Pedagogia. Integrante do NUSEX Núcleo de Estudos da Sexualidade (UNESP). Ituverava - SP - Brasil. fatinini@yahoo.com.br
} 
cidadão consciente de seus direitos e deveres, ainda é a especificidade e função inerente da escola.

Desta feita, na atualidade o exercício lógico da cidadania é construído principalmente, pela instrução, tendo papel em destaque a escola e conseqüentemente seus protagonistas. Assim, os professores, que fazem parte desse cenário escolar, necessitam ter uma formação efetiva, bem como, ter sua trajetória de vida pessoal, escolar e profissional respeitada, pois são fatores relevantes na construção da representação a respeito do ambiente que irá atuar como docente.

Parte-se da premissa que o ser professor não é inato, é construída e constantemente reconstruída, construção essa que carrega consigo vivências e saberes inerentes a cada pessoa se estendendo durante a formação; pressupondo-se que nesse processo há reconstruções das representações que embatem com suas expectativas e necessidades, desencadeando angústias, expectativas, medo, insegurança em relação a prática docente.

Corroborando com esse pressuposto Dubar (1997, p.77) adverte que o ser professor faz parte da identidade de cada profissional e ressalta que:

[...] a identidade humana não é dada, de uma vez por todas, no ato do nascimento: constrói-se na infância e deve reconstruir-se sempre ao longo da vida. O indivíduo nunca constrói [sua identidade] sozinho: depende tanto dos julgamentos dos outros, como das suas próprias orientações e autodefinições [...], a identidade é produto de sucessivas socializações.

Para a realização desse estudo, analisaram-se as representações das alunas do Curso de Pedagogia de uma Universidade do interior paulista, fundamentado na Teoria das Representações Sociais propostas por Serge Moscovici (1961), sobre a concepção e seus caminhos de escolarização e a relação com a formação docente, abstraindo atitudes, comportamentos, falas, diálogos e acontecimentos ocorridos na trajetória escolar vivenciadas pelas participantes da pesquisa.

Foi possível percebe-se que ao privilegiar as representações sociais a pesquisa possibilitou reflexões sobre as atitudes de educadores no ambiente escolar tanto no ensino básico como na universidade, e como se da à formação dos docentes a constituição da relação entre prática e teoria.

\section{A Teoria das Representações Sociais (TRS) como fundamentação teórica}


A teoria adotada para analisar as representações de alunas do curso de Pedagogia sobre os caminhos da escolarização e a relação com a formação docente, foi preconizado por Moscovici (2003) que se refere às representações sociais como um conjunto de conceitos, proposições e explicações advindas da vida cotidiana e das comunicações interpessoais.

De acordo com Jodelet (2001, p.21), a representação é uma “[...] forma de conhecimento, socialmente elaborado e partilhado, com um objetivo prático, e que contribui para a construção de uma realidade comum a um conjunto social [...]” apresentando uma visão prática que concorre para a construção de uma realidade comum a um conjunto social.

Essas definições permitem perceber que as representações sociais se apóiam em valores dos grupos sociais de onde partem significações, valores ideológicos e culturais, conhecimentos científicos, experiências particulares e afetivas do indivíduo.

Segundo Moscovici (2003), para se construir as representações sociais é necessário envolver, ao mesmo tempo, a proposição de uma identidade e de uma interpretação da realidade. Para o autor, quando os sujeitos sociais constroem e organizam campos representacionais, eles o fazem de forma a dar sentido à realidade, a apropriá-la e interpretála. Quando o fazem, dizem quem são, como entendem a si mesmos e aos outros, como se situam no campo social e quais são os recursos cognitivos e afetivos que lhes são acessíveis, num dado momento histórico.

\section{Caminhos da pesquisa}

O presente estudo utilizou a metodologia de caráter qualitativo. O estudo foi desenvolvido em quatro etapas. As três primeiras etapas foram o desenvolvimento de redações pelas participantes da pesquisa e a última etapa foi a realização de uma entrevista semi-diretiva, individual e gravada com as participantes.

O primeiro momento aconteceu quando as participantes do estudo estavam iniciando sua trajetória do curso de pedagogia. Foi solicitado então, que estas escrevessem a sua trajetória escolar. A segunda etapa do trabalho foi constituída pela narração do que mudou na vida das participantes após seu ingresso no $1^{\circ}$ ano do curso de pedagogia. O terceiro momento do trabalho foi identificado com a descrição das participantes de como o $2^{\circ}$ ano do curso de pedagogia contribuiu para o processo de sua formação como professor. Finalizando a etapa das redações, as participantes foram convidadas a escreverem qual a contribuição que o $3^{\circ}$ ano do curso de pedagogia proporcionou para o seu futuro trabalho como docente. Para concluir 
ocorreu a realização de uma entrevista semi-estruturada quando as alunas já se encontravam no último semestre do curso.

É importante ressaltar que no início do estudo havia a participação de 23 alunas do curso de pedagogia, sendo que apenas 20 alunas participaram da primeira redação do estudo, 18 alunas participaram da segunda etapa do estudo e apenas 18 alunas participaram da quarta redação do trabalho. Em relação às entrevistas, apenas 14 alunas participaram desse momento do trabalho.

Cabe destacar que o presente trabalho respeitou todos os preceitos éticos exigidos para a realização de pesquisa dessa natureza.

\section{A análise e alguns resultados}

Para analise dos dados, de caráter qualitativo, centrou-se na metodologia de análise de conteúdo, modalidade temática (BARDIN, 1995). Ao realizar uma análise temática é necessário reconhecer núcleos de sentido, que são manifestos devido à freqüência ou à própria presença, apresentando significação para o objeto em estudo. Portanto, a análise qualitativa, mostra-se através de valores, inferências e preceitos referentes ao tema pesquisado.

Após a análise das redações das participantes do estudo, foi identificado, tabus, preconceitos, medos, inseguranças, expectativas e incertezas em relação à profissão escolhida. Há na escrita das participantes confusões entre os aspectos positivos e negativos do curso; relatos de que a postura do docente, ou seja, o formador de novos docentes, ainda é muito arraigada na ideologia dominante; a grande maioria relata ter tido mudanças de paradigma em relação a sua vida e aos contextos sociais, se tornando mais críticas e reflexivas nas suas opiniões, mas que apesar das mudanças advindas da formação universitária, ainda há o medo e a insegurança quanto a execução da atividade profissional como docente, visto que, o curso foi muito rápido e com pouca prática, deixando uma lacuna na formação docente.

Percebe-se ainda nos discurso das pesquisadas que a representação que tem do curso de pedagogia, é algo ainda negativo, pois, relatam na maioria das vezes, que a profissão de Pedagogo ou professor é uma profissão desvalorizada, mal remunerada e exaustiva e que na prática docente que estas alunas tiveram no momento do estágio, verificaram a ausência de subsídios nas escolas para trabalhar, gerando insegurança profissional para a docência.

Quanto à opção pelo Pedagogia, verifica-se que há a busca devido à identificação natural pelo curso ou devido à necessidade imposta pelo mercado de trabalho, ou ainda uma escolha influenciada por uma pessoa da família ou outro profissional. 


\section{Análise do esquema do núcleo figurativo}

O esquema a seguir é baseado nos processos formadores das representações sociais (objetivação e ancoragem) e revela a construção de análise dos resultados de acordo com a (TRS).

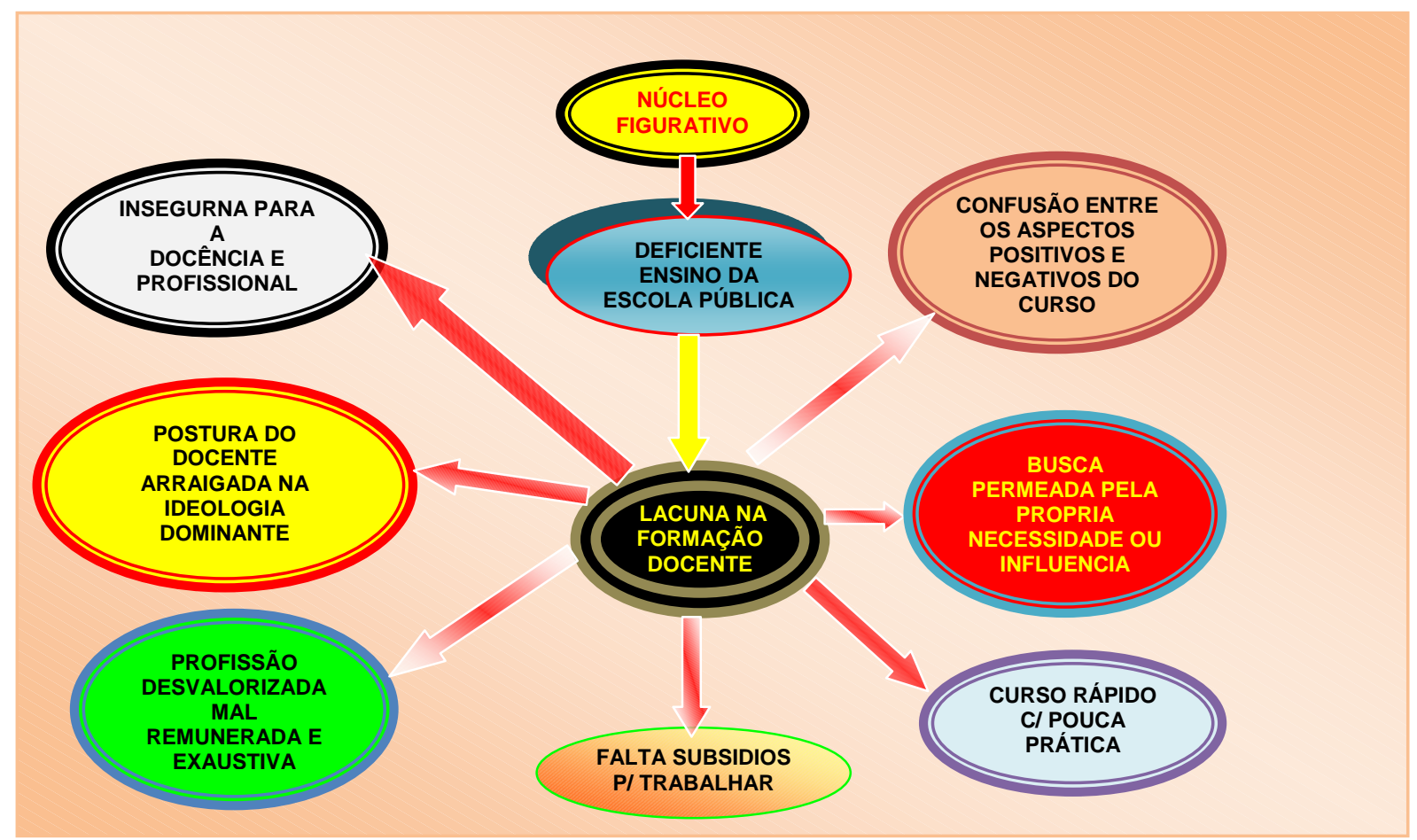

Figura 1 - Fluxograma do Núcleo Figurativo. ${ }^{4}$

Neste estudo, os participantes não são receptores passivos. Os fenômenos por eles vivenciados necessitam ser discutidos e explicados em função da pertença ao grupo social. Como afirma Moscovici (2003), as representações são criadas para ocultar ou elaborar imagens de uma realidade objetiva, proporcionar estabilidade interna do grupo e guiar o comportamento individual entre os membros desse grupo.

Neste trabalho, os sujeitos em questão são as alunas do curso de pedagogia, sendo seus caminhos de escolarização e a relação com a formação docente o objeto de representação, pois por ser um grupo em condições de formação análogas é possível que construam uma relação de simbolização com o próprio objeto em questão, sendo uma

\footnotetext{
${ }^{4}$ Esse fluxograma representa a análise dos processos formadores das Representações Sociais obtidos nesse estudo. Figura elaborada no Microsoft Word XP - Ferramentas de Desenho.
} 
representação em que todas possam partilhar.

O processo de escolarização trata-se de uma etapa importante na vida das pessoas e suscita lembranças para os profissionais, inclusive os que trabalham com questões educacionais, como demonstra a fala a seguir:

[...] lembro até hoje o nome da minha primeira professora era a D. Antonia, pois foi ela que me alfabetizou, pois eu não sabia nada nem números e nem letra [...] (9, estudante de Pedagogia, relato no início do $1^{\circ}$ ano do curso).

Corroborando com essa idéia destaca-se:

[...] uma boa parte do que os professores sabem sobre o ensino, sobre os papéis do professor e sobre como ensinar provém de sua própria história de vida, principalmente de sua socialização enquanto alunos. Os professores são trabalhadores que foram imersos em seu lugar de trabalho durante aproximadamente 16 anos (em torno de 15.000 horas), antes mesmo de começarem a trabalhar. Essa imersão se expressa em toda uma bagagem de conhecimentos anteriores, de crenças, de representações e de certezas sobre a prática docente. (TARDIF; RAYMOND, 2000, p.4).

Os estudantes de pedagogia envoltos neste estudo também possuem recordações caracterizadas como boas e ruins sobre os primeiros anos de escolarização. Acreditam que o estudo universitário seja um sonho para a maioria das pessoas, mas a universidade ainda é o caminho, capaz de proporcionar mudanças pessoais, culturais e sociais:

[...] apesar de toda dificuldade em cuidar de casa, trabalhar decide realizar o sonho de infância, que se tornou agora mais importante, pois busco junto a ele realização financeira. (10 - estudantes de Pedagogia, relato no início do $1^{\circ}$ ano do curso).

[...] não tive incentivo nenhum da escola para "um dia ingressar na faculdade”, [...] e hoje esse dia chegou graças ao apoio [...] e do meu sonho que sempre foi maior e mais forte que tudo. (2 - estudante de Pedagogia, relato no início do $1^{\circ}$ ano do curso).

A entrada no curso universitário apresenta-se como importante fator de realização pessoal em primeiro momento e futuramente relacionado ao fator profissional, e mesmo diante das adversidades, estudar é algo relevante para o próprio educando.

Tendo a teoria das representações sociais como referencial teórico deste trabalho, buscou-se identificar os processos de objetivação e ancoragem, ambos formadores de tal teoria, para interpretar como as representações sociais se formam.

Por meio da objetivação, dimensão mais cognitiva da representação, o indivíduo transforma um conceito abstrato em algo concreto, isto é, torna-se familiar o estranho, o 
desconhecido; “[...] transferir o que está na mente em algo que exista no mundo físico” (MOSCOVI, 2003, p.61).

A ancoragem apresenta-se como dimensão predominantemente social da representação, transforma algo desconhecido em familiar; a ancoragem nos auxilia a entender o que pode ser considerado "ameaçador"; a ancoragem nos ajuda a enfrentar as dificuldades de compreender ou definir situações; “[...] ancorar é, pois, classificar e dar nome a alguma coisa” (MOSCOVICI, 2003, p.61).

Analisando as narrativas foi possível constatar que as representações sociais construídas pela alunas do curso de pedagogia têm como elemento marcante, a deficiência do ensino básico público, o qual dificulta o acesso a universidade pública e boa formação profissional. Assim essa característica constitui-se o núcleo figurativo da representação social. O qual nesse estudo é a deficiência no ensino da escola publica.

Moscovici (2003, p.72) designou que na elaboração da Representação Social, “[...] as imagens que foram selecionadas, devido a sua capacidade de ser representadas, se mesclam, ou melhor, são integradas no que eu chamei de um padrão de núcleo figurativo, um complexo de imagens que reproduzem visivelmente um complexo de idéias”. O núcleo figurativo fica pautado pela própria história de vida enquanto aluno na trajetória escolar, modelo a ser seguido e ser repelido.

Assim, a objetivação tendo como marca a capacidade de atribuir significados, fica representada por uma amálgama entre os pontos positivos e negativos do curso; quais sejam no que se refere ao positivo se expressa por “construir” uma visão crítica, reflexiva, melhores possibilidades no mercado de trabalho; e negativa a insegurança, o pouco preparo para a docência e na própria profissão:

[...] sinto que as coisas mudaram ao ponto de eu poder dizer que agora enxergo o mundo, as pessoas, a política, a arte, os movimentos, as transformações, os sons, as ciências, as diferenças, o passado [...] sinto-me responsável por fazer algo de bom [...] [...] Sai de um olhar ingênuo para uma visão crítica (1 - aluna do curso de pedagogia).

[...] tenho a sensação de ter saboreado um terço da fatia do bolo e para ser uma boa profissional ainda tenho que buscar muito, estudar bastante. (2 aluna do curso de pedagogia).

Nesse contexto, os caminhos de escolarização e a relação com a formação docente, ficam ancorados em uma lacuna da formação profissional que interfere, sobremaneira, em todo o processo educativo do indivíduo, gerando medo, insegurança para atuar na docência. 
É importante ressaltar que o núcleo figurativo desse estudo se ancora na própria vivência que as alunas tiveram na trajetória escolar desde a sua iniciação até o momento que fizeram estágios como docentes.

Estas verificaram que a profissão escolhida era permeada por ausência de subsídios para trabalhar, desvalorizada, mal remunerada, exaustiva e que o curso de graduação deixou a desejar, por ser um curso rápido, que oferece pouca prática e com alguns docentes arraigados na ideologia dominante, apesar de ser um curso considerado pelas participantes, teoricamente bem embasado, tendo estas o imaginário de que conseguirão, transpor as barreiras políticas econômicas e sociais que perpassam a educação e promoverão mudanças, como pode-se observar nas narrativas a seguir:

[...] vou tentar aplicar ao máximo toda teoria [...] tenho certeza que se eu conseguir aplicá-las na escola em que eu trabalhar [...] terei um sucesso profissional ( 9 - alunas do curso de pedagogia).

[...] quero ser aquela professora que as crianças não esquecem que sempre vai ser lembrada como que fez e realizou grande coisa ( grifo da aluna) para suas vidas. E com certeza as arvores que irei plantar vão crescer e dar grandes e belos frutos ( 3 - aluna do curso de pedagogia).

[...] Criança é a criatura mais doce e meiga que tem [...] quero ser uma ótima professora quero fazer tudo para eles serem felizes. (6 - aluna do curso de pedagogia).

Nessa perspectiva, percebe-se que as participantes têm referencias marcantes tanto dos aspectos positivos e negativos gerando críticas contundentes em relação à escola pública, tais como: professores desmotivados, professores que não incentivam os alunos, greves docentes, entre outros aspectos que desvaloriza o ensino publico. Na representação das participantes, os alunos do curso de pedagogia são marcados por um "desconforto" em ver a sociedade dessa forma.

Sucintamente, este estudo demonstrou que a formação docente é parte central para a mudança, no intuito de cristalizar ideais e formar docentes capazes de realizar a relação teoria e prática, conforme destaca Pacheco e Flores (1999, p.45) “[...] um professor não nasce nem se vincula pela mística do sacerdócio ou pela idéia do artístico, daí que o seu percurso formativo inclua processos de aprendizagem contínua, de caráter formal e não formal.”

Sendo assim, pressupõe-se ser necessário que os cursos de formação docente organizem suas grades curriculares tornando-as também mais adequadas a sociedade atual, 
principalmente em se tratando do profissional da educação básica buscando melhoria do conhecimento e da prática como docente.

\section{SOCIAL REPRESENTATIONS OF PEDAGOGY COURSE STUDENTS: EXPECTATIONS REGARDING THE TEACHER FORMATION}

ABSTRACT: This present paper analyzed pedagogy students' representations regarding the schooling process and teacher formation. The research is based on Moscovici's social representations theory, studies about teacher formation and the schooling path. The paper is consisted of four steps that took place during a Pedagogy course formation process, three of these steps consisted in the students writing a composition on three different moments during the course; lastly, interviews with the students were recorded. The data was analyzed though the content analysis, a thematic modality, for the gathering of signification nucleuses. The representations constructed by the participants have the deficiency of public elementary school as an element that stands out, as it makes the access to a public college and a good professional formation difficult, and it constitutes social representation's figurative nucleus. The future teachers have also revealed insecurity and fear regarding the ability to exercise the teaching profession, but they also indicated positive points on the course: it is marked by criticism, reflection and a better insertion in the labor market. It was possible to verify the importance of training teachers for education improvement, especially teachers who will work on the early education process. Such training should be based on the relationship between theory and practice and also on rescuing the role of the educator on today's society. KEYWORDS: Social representations. Teacher formation. Pedagogy course

\section{REFERÊNCIAS}

BARDIN, L. Análise de conteúdo. Lisboa: Edições 70, 1995.

DUBAR, C. A socialização: construção das identidades sociais e profissionais. Porto: Porto Editorial, 1997.

JODELET, D. Representações sociais: um domínio em expansão. In: JODELET, D. (Org). As representações sociais. Rio de Janeiro: Eduerj, 2001. p.17-44.

MIZUKAMI, M. da G. N. Docência, trajetória pessoias e desenvolvimento profissional. In: REALI, A. M. M. R.; MIZUKAMI, M. G. N. (Org.). Formação de professores: tendências atuais. São Carlos: EdUFSCar, 1996. p.59-89.

MOSCOVICI, S. Representações sociais: investigações em psicologia social. Tradução de Pedrinho A. Guareschi. Petrópolis: Vozes, 2003. 
PACHECO, J. A.; FLORES, M. A. Formação e avaliação de professores. Porto: Porto Editora, 1999.

PIMENTA, S. G.; LIMA, M. S. L. Estágio e docência. São Paulo: Cortez, 2004.

TARDIF, M.; LESSARD, C. O trabalho do docente: elementos para uma teoria da docência como profissão de interações humanas. Petrópolis: Vozes, 2007.

TARDIF, M.; RAYMOND, D. Saberes, tempo e aprendizagem do trabalho no magistério. Educação e sociedade, Campinas, v.21, n.73, dez. 2000.Disponível em:

<http://www.scielo.br/scielo.php?script = sci_arttext\&ped=S0101- 733020.00000400013 \&Ing = fev.2009.doi:10.1590/S0 101- 73302000000400013. Acesso em: 19 nov. 2008.

TURA, M. L. R. A representação social do ser professora. In: JORNADA INTERNACIONAL SOBRE REPRESENTAÇÃO SOCIAL, 4., 2005, João Pessoa. Textos completos: teoria, metodologia e intervenção. João Pessoa: Editora Universitária UFPB, 2005. v.1. p. 620-635. 1 CD-ROM. 